\title{
Information System for the Formation of Students' Individual Educational Trajectory
}

\author{
Sergii Sharov ${ }^{1}$, Dmytro Lubko ${ }^{2}$, Oleksandr Lomeiko ${ }^{3}$, Hanna Chemerys ${ }^{4}$ \\ \{segsharov@gmail.com ${ }^{1}$ \}
1,2,3 Dmytro Motornyi Tavria State Agrotechnological University, 18 Bogdan Khmelnitsky Ave., Melitopol, 72312, Ukraine
${ }^{4}$ Zaporizhzhia National University, 66 Zhukovsky str., Zaporizhzhia, 69600, Ukraine

\begin{abstract}
The article deals with the development of a multi-user information system for the formation of students' individual educational trajectory; it describes the main functional capabilities of the electronic resource. It is noted that a competence approach and individual educational trajectories allow taking into consideration the individual learning features and interests of students; they prepare them better for future professional activities. The use of information systems affects the effectiveness of managerial, educational, and administrative processes. The authors analyze the areas where information systems can be used in higher education institutions. The functional capabilities of the information system for the formation of students' individual educational trajectory are considered. The information system works in the "administrator" and "student" modes; it allows forming an individual curriculum plan for the student, to store official information on students and teachers, as well as curricula on various specialties, and to make reports according to different criteria. In future, it is planned to add the types of users who have different rights to enter and view information.
\end{abstract}

Keywords: Educational Trajectory; Education; Students

\section{Introduction}

Modern living conditions require of people to develop new forms of thinking, behavior and cooperation. People must be responsible for their own actions, be able to find and master new knowledge as quickly as possible, to make adequate decisions according to the situation.

Today, education, especially higher education, remains a major factor of social and economic progress. It provides students with academic knowledge; it helps them to develop professional skills that they will need in their future profession [1]. On the other hand, an effective educational process is impossible without the systematic and planned work of students, without their focus on self-education and self-realization [2].

Keeping this in mind, there is a need to implement personality-oriented learning (that is a focus on students' individual abilities and demands) and a competence approach to the process of student training. According to researchers [3], [4], the competence approach involves the formation of a set of competences according to the chosen profession. The formation and development of individual competences occurs through the study of relevant educational components (academic disciplines). In turn, competences are considered to be a set of internal and external resources to solve professional and social tasks. Thus, conditions are created for students' cultural and personal development, and responsibility is formed for the results of personal training. 
In order to realize the educational potential in full, the student must form an individual educational trajectory which is characterized by dynamism and versatility [2], profound training within professional and educational interests. The use of individual educational trajectories in the process of student training will increase their competitiveness in the labor market; it will expand academic mobility and accelerate the pace of socio-economic development [5].

The individual educational trajectory involves:

a. an independent choice of elective courses which most fully meet the educational interests of students.

b. a choice of topics for diploma and term papers, as well as bases for training and production practices.

c. taking additional courses (in person or remotely) in order to form additional competences, etc.

The rapid development of information and communication technologies (ICT) and their introduction into the educational process has led to the emergence of new pedagogical technologies and methods of teaching, changes in the structure and content of education. One of the directions of the educational process modernization is a practical solution to the problem of education informatization. This process should take place with respect to the informatization experience in other areas, including business [6].

A significant factor in raising education to a new level is equipping educational institutions with computers, as well as development and implementation of quality software. The same goes for ensuring the individual educational trajectory of pupils / students. Modern computerbased teaching aids, in comparison with traditional teaching aids, provide new educational opportunities, allow practical implementation of the latest teaching techniques, and stimulate the development of methods and didactics.

The introduction of ICT is observed in educational institutions of different accreditation levels. For example, electronic textbooks [7] are actively used in schools. They are developed on the initiative of the authors or within the all-Ukrainian experiment "E-book for secondary education (EBSE)" which is carried out from 2018 to 2021. In the educational process of higher education institutions mass open online courses (MOOC) and distance learning systems are effectively used [8]. In Ukraine, the most common MOOC are the Prometheus, EdEra and OUM [9] which have been actively developing since 2014. Learning with the help of MOOC a priori involves high motivation of students and their focus on self-education. For more effective formation of an educational trajectory by means of MOOC, it is possible to use genetic algorithm or possibilities of neural networks [10]. In order to implement personalityoriented learning, individual learning systems begin to develop [11]. Their key feature is the possibility of synchronization with the educational process and dynamic adaptation to the results of student learning activities.

In addition to the introduction of the Internet and cloud technologies in the educational process, today we can see the active use of information systems to automate learning and managerial activities. Management information systems are implemented at the level of the educational institution and they have a multi-module structure. Depending on the scale, they may consist either of managerial, organizational, educational and scientific [12], or economic, financial, educational and scientific [13] components. It is effective to use information systems to maintain public relations which help to increase the competitiveness of a higher education institution [14].

In order to support the educational process and take into account the individual educational trajectory, information systems of learning analytics are used. With their help, teachers can 
update educational content within the academic discipline in accordance with the students' learning outcomes [15]. Another type of information systems can use the results of assessments (exams, credits) to form a student rating according to different criteria [16]. Despite the existence of different-type information systems that provide training and individual educational trajectories, a promising task is to create information systems for the formation of a student's individual educational trajectory.

\section{Methodology}

The development of an information system to form students' individual educational trajectory involved the following tasks:

a. Curricula analysis (we used the curricula for specialty 122 "Computer Sciences" as examples);

b. Making general requirements for the electronic course with respect to the specific features of information systems and the concept of "individual educational trajectory";

c. Making a design of the information system structure;

d. Choosing the tools (programming environment and database for information storage) to develop the information system;

e. Development of the information resource modules and testing their efficiency;

f. Selection and registration of a domain name for the correct operation of the information system;

g. Detection and correction of errors in the work of the information resource;

h. Uploading official information about curricula, users, etc. Into the information system.

At the beginning of the information system development for the formation of students' individual educational trajectory, it was assumed that the system should provide registered users with access to curricula, students' individual educational trajectories, as well as generate reports according to various criteria for further data analysis. The initial functional capabilities that the information system should provide are:

a. Creation, editing and approval of the curriculum for a certain educational program;

b. Student's choice of free-choice disciplines from the list of elective courses in the curriculum;

c. Formation of an individual curriculum plan by the student;

d. Display of information about disciplines in the form of annotations / syllabuses;

e. Display of information about teachers (lecturers) who teach certain disciplines;

f. Generating reports for students / teachers according to different criteria;

g. Generating a report for the head of the department or the educational department staff which will help analyze the approximate workload at the department on the basis of freechoice disciplines.

The general scheme of the information system for the formation of students' individual educational trajectory is reflected in Figure 1. 


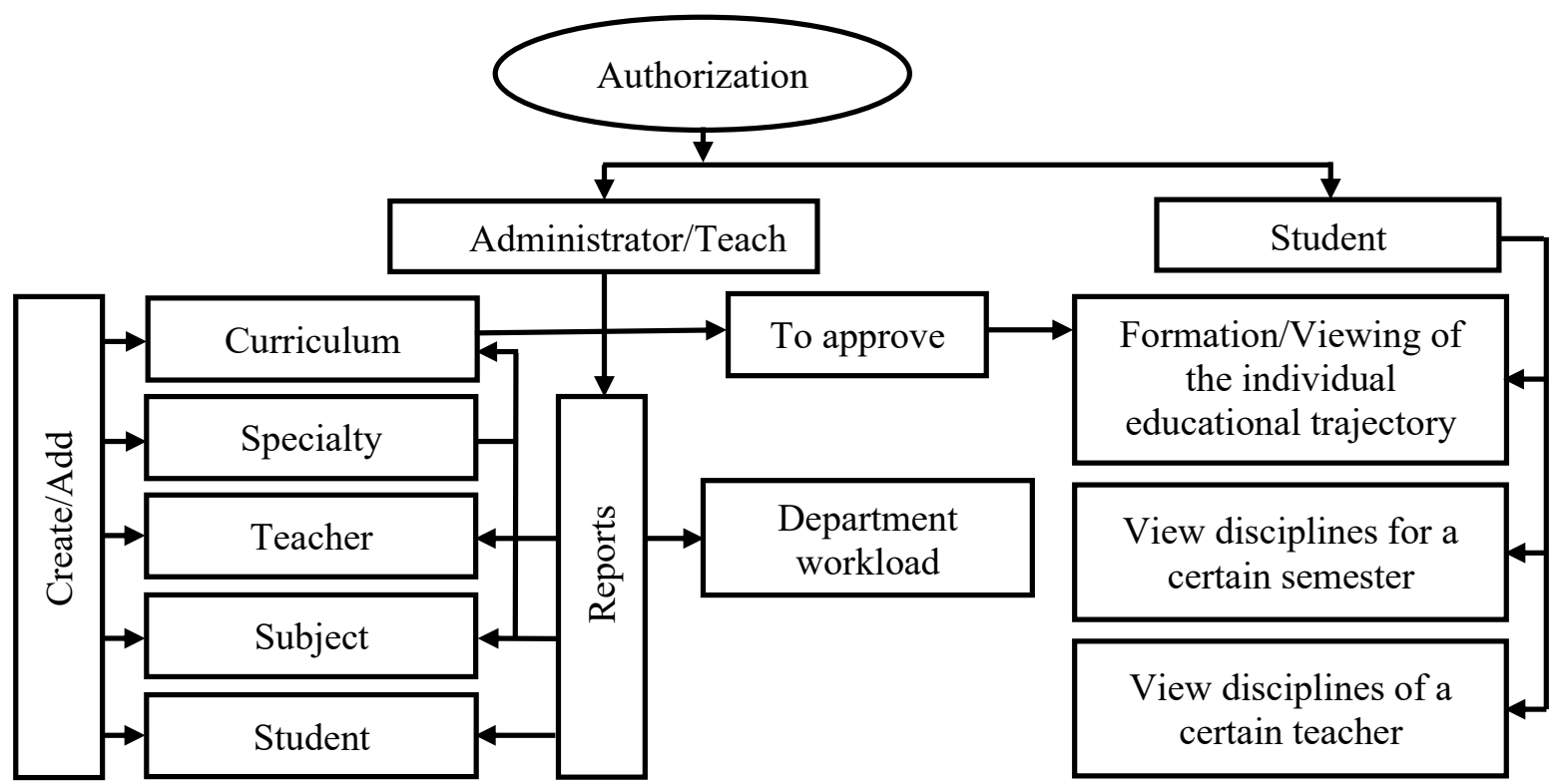

Figure 1. The General Scheme of the Information System

The PHP programming language was chosen as a tool for the information system development. It is free, it has powerful capabilities for web application development, and it is supported by many programming environments. MYSQL software was used to store the data, which allows many users to work with the data; it is distributed under the GNU GPL license, and it fully supports the relational data model. Development of the database structure, creation of links between tables was performed with PhpMyAdmin. To ensure security against the use of malicious SQL-queries, software validation was performed on each page where data is entered into the form fields. Using the PDO library (PHP DataObjects) allowed screening the data and eliminating the possibility of SQL-injections.

\section{Result and Discussion}

The information system works in administrator and user mode. If the entered login and password match the administrator login, the user is authorized as an administrator. Otherwise, the entered data are compared with the student data. If the login / password do not match, the user sees an authorization error. It should be noted that the user must be registered in the information system to work in it. User registration is performed by the administrator. Let us have a more precise look at the functional capabilities of the information system in both modes.

In the "Student" mode, the users can view the curriculum, form their own individual curriculum plans, display the subjects of the selected semester, or display the subjects of the selected teacher. When activating the "Curriculum" option, a page with a curriculum table becomes available to the user. There, the subjects of the compulsory block and lists of freechoice disciplines are displayed. If the lists have not been selected, the fields of the selected disciplines will be empty with further possibility to choose a certain discipline from the 
proposed ones. If all the disciplines have been completed, the table will show the corresponding changes (Figure 2).

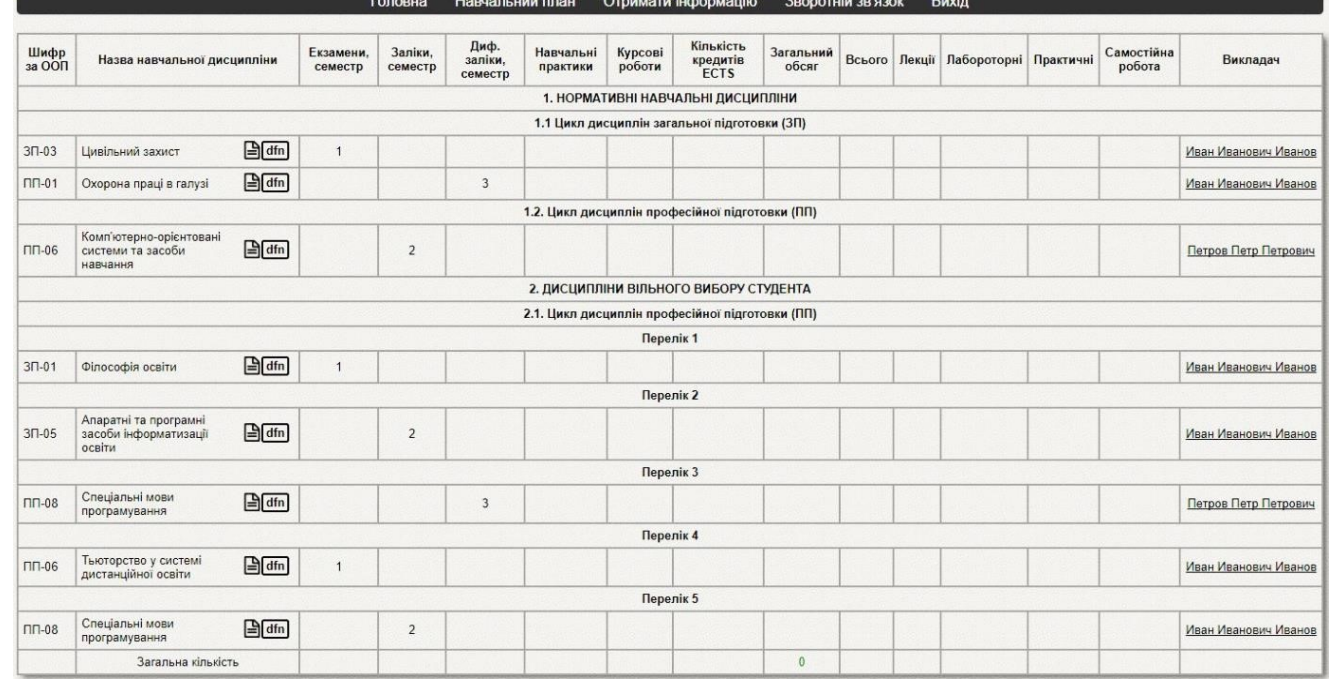

Figure 2. Student Individual Curriculum Plan

Each discipline is accompanied by an annotation or syllabus, as well as a link to an online course in the Moodle system. Documents and links are downloaded separately by the administrator. If you need to get additional information about a certain teacher, you should activate the appropriate link. Then, the necessary information will appear (the teacher's name, department, or the classroom where classes are held).

Once the individual curriculum has been fully formed and the required number of hours in all subjects has been achieved, it must be approved (the function is implemented in the administrator mode). Validation of a specific curriculum is explained by the need to take into account the selected disciplines when calculating the teachers' workload at the department.

You can generate several reports in the "Student" mode. Thus, it is possible to display the subjects of a certain semester in the form of a table. To do this, one should activate the appropriate link and select the semester number. For students, this is a very useful feature that allows them to be aware of all the subjects taught in a certain semester.

Also, a useful function of the information system is to display the subjects taught by a certain teacher. To do this, you need to activate the appropriate link and select a teacher. After that, the user will be able to see a sample from the individual curriculum plan which includes the disciplines of a particular teacher.

In the "Administrator" mode, users can use the following functions: to add the necessary service information, to create a curriculum, to assign a teacher to a particular discipline in the curriculum. They can also view the individual curriculum plan of different students, unapproved curricula, subjects of a particular teacher, the approximate workload at the department according to the disciplines chosen by students, information on the number of students who chose particular elective courses (Figure 3). 


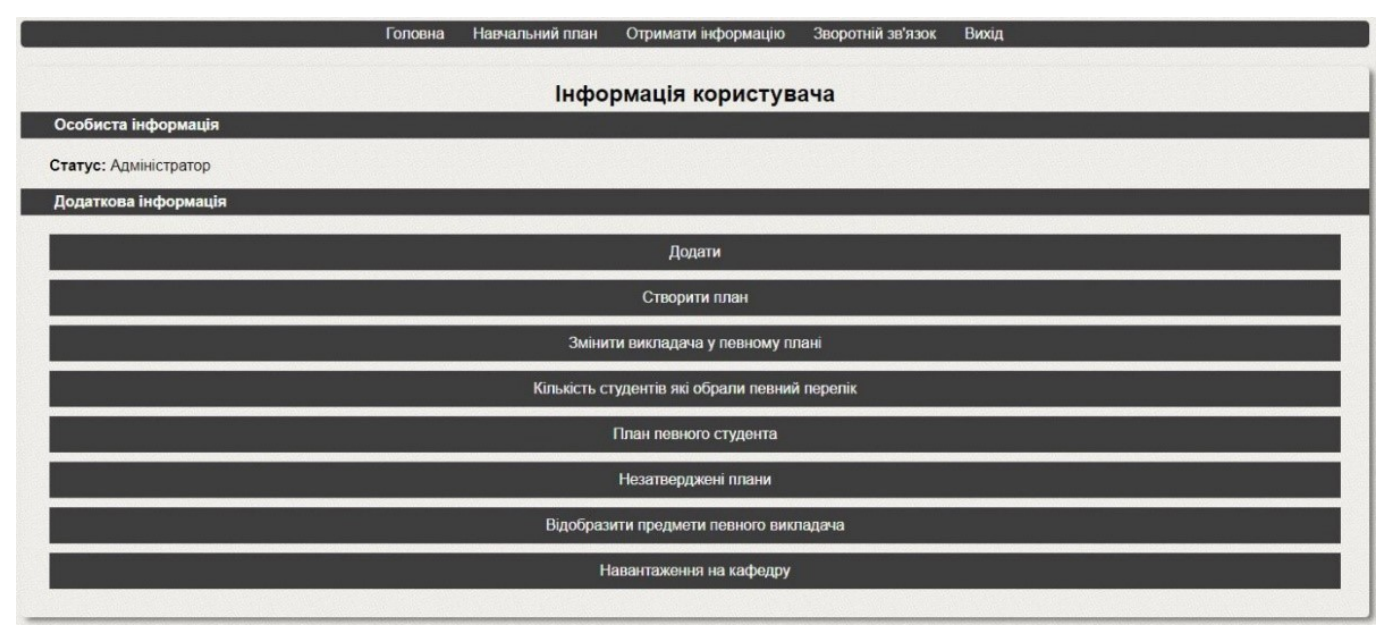

Figure 3. The Administrator's Bar

With the help of the "Add" page you can add official information about specialties, students, teachers and subjects (Figure 4).

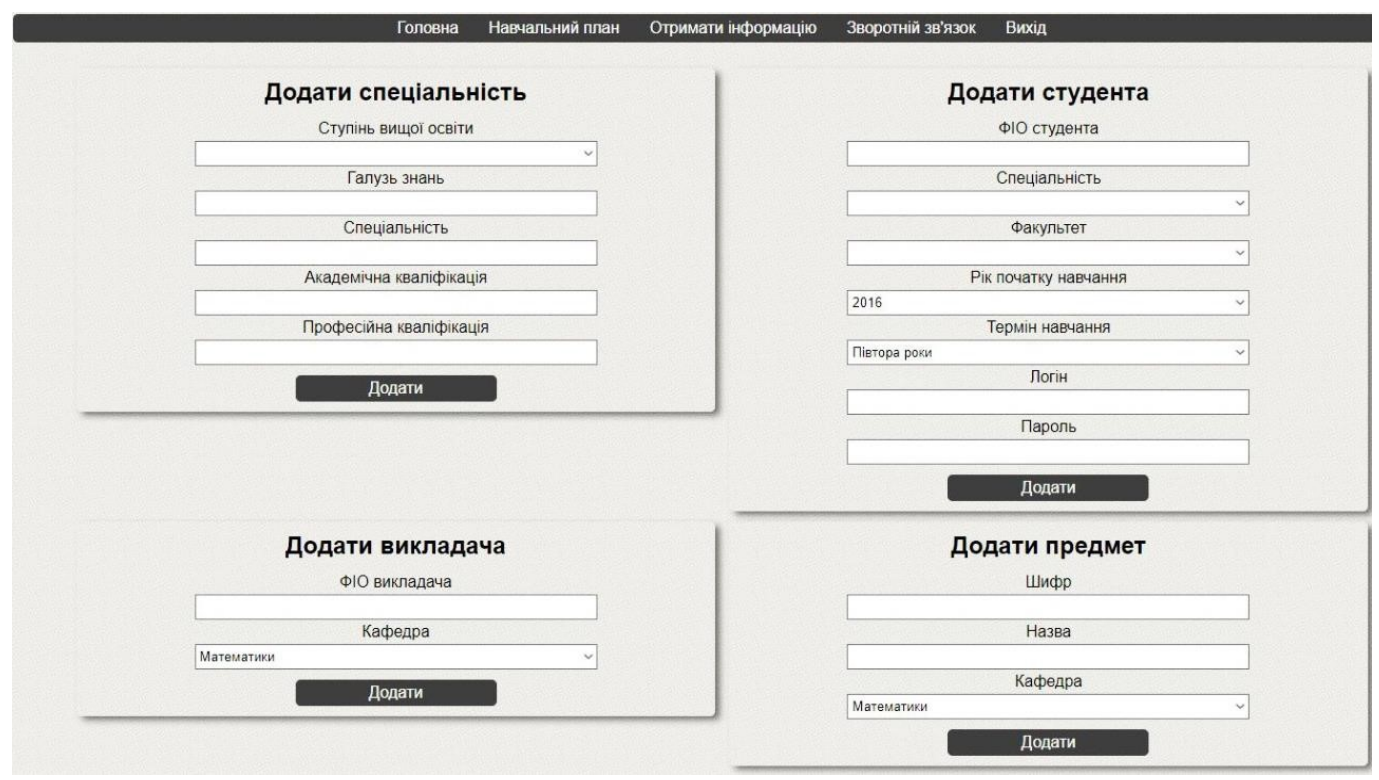

Figure 4. Windows for Adding Specialties, Students, Teachers, Subjects

The "Create Plan" page consists of a block that contains information about the specialty and a block that contains a table for adding items. Creating a curriculum involves choosing the right specialty (created in advance), determining the year of beginning and end of training, the term of study. After these actions, users get access to a template of a new curriculum in the form of a table where they need to enter the names of teachers, disciplines, exams, credits, practices, term papers, lectures, laboratory works, practical and self-study works. Then, they click the "Confirm" button. Once a plan has been created, it must be approved. You need to 
select the item "Unapproved plans", select the required plan, correct errors if necessary, and approve it.

During the educational process, there might be a need to change the teacher who teaches a certain discipline. In this case, go to the "Change teacher in a certain plan" option, select the required curriculum and change the teacher.

Several reports are available to the administrator. If necessary, you can display the subjects taught by a particular teacher in a particular curriculum. To do this, select the option of "Display subjects of a certain teacher", select the teacher, the curriculum of the year required and specialty, click the "Display" button. Reporting information will be presented in the form of a table which contains the subjects of a particular teacher.

The page "Number of students who have chosen a certain list" displays a generalized list of subjects and the number of students who have chosen a particular elective course (Figure $5)$.

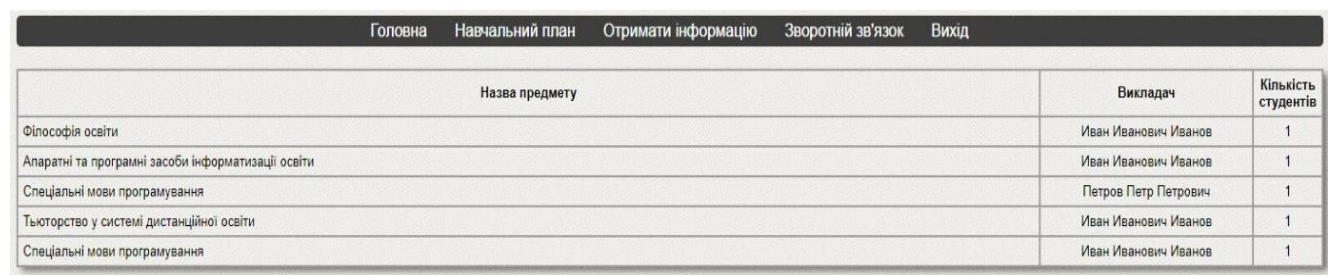

Figure 5. Information About Students who Have Chosen Individual Elective Courses

A generalized report showing the department workload will be useful for the heads of the departments, the dean's office and the educational department staff. To do this, use the option of "The department workload", select the year of study, the department, and click the "Display" button. After these actions you will see the table which contains disciplines from all the curricula which are taught by the teachers of the chosen department.

The application of the developed information system meets modern requirements, in particular the provision of a competence approach in course of specialist training. It is the competence approach that allows combining the requirements set by employers for specialists and the opportunities provided by higher education institutions [3], [4]. Also, it increases the competitiveness of future professionals. Regarding the education informatization, information systems allow improving the quality of administrative, educational, social processes in the activity of higher education institutions [13], [14], [16].

As for the formation of an individual educational trajectory, users of the information system can focus on the curriculum of the educational program, they can choose educational components from the block of free-choice disciplines, and follow their own educational trajectory as a list of educational components. The mechanism for selecting elective courses should be provided at the level of the higher education institution and it should be prescribed in the corresponding guidelines.

At the same time, appropriate pedagogical conditions must be provided for the correct choice of academic disciplines and for the formation of an individual educational trajectory. These include the formation of students' motivation to acquire new knowledge and professional self-development, to develop independence [2], to monitor their academic achievements and psychological readiness [5] for a more adequate choice of disciplines. It should be noted that the individual educational trajectory is also realized through the educational content, applied forms of learning [1], the use of interactive pedagogical 
technologies within a particular discipline, including project method, game methods, cases [5], etc.

The developed information system is available only for registered users, in particular students, teachers and heads of relevant departments. This will allow obtaining complete information about the individual choice of a particular student, as well as generating information reports according to various criteria in case the access is available. Authorized access and identification of the participant of the educational process in the information system can be considered an advantage of such software products [12]. In our study, a promising task is to create additional types of users (teachers, authorities) and provide them with different rights. In addition, the usefulness of the step-by-step introduction of ICT in higher education [6] emphasizes the need to develop additional modules that would allow storage of students' performance and other information.

\section{Conclusion}

Thus, the use of individual educational trajectories in the educational process is a condition for effective specialist training for professional activities. The use of ICT, in particular information systems, in higher education institutions will increase the efficiency of managerial and educational processes, and it will ensure the formation of personality-oriented learning.

The developed information system meets the needs of teachers and students while working with individual educational trajectories. It provides convenient and quick access to the curriculum of a specialty, to individual curricula plans of students, syllabuses / annotations of disciplines; it allows you to calculate the department workload based on the results of students' choice of elective courses. All the data are received, processed and entered into the database which provides a possibility to store official information and to generate reports according to various criteria as many times as necessary.

In future, it is expected to increase the number of users of the information system who will have different access rights to its functional capabilities. It is also planned to integrate a module into the information system that is responsible for the results of students' learning activities.

\section{References}

[1] T. O. Krasnopeeva, A. I. Shevchenko, and I. V. Romanova, "How to create individual educational trajectories in the informational educational environment," SHS Web Conf., vol. 87, 2020, doi: 10.1051/shsconf/20208700003.

[2] I. N. Odarich, A. R. Yagudina, A. V. Vorontsova, M. A. Oleynik, and O. E. Vinokurova, "A system for identifying and developing of individual student's learning ways," Univ. y Soc., vol. 12, no. 2, 2020.

[3] Y. Y. Orekhova and M. V. Badelina, "Role of students' scientific research in implementation of competency approach in technical university," Int. J. Civ. Eng. Technol., vol. 10, no. 1, 2019.

[4] A. H. Zineb, B. Soumia, A. Souad, and G. Karim, "The application of the competencybased approach to assess the training and employment adequacy problem," arXiv. 2017, doi: 10.5121/ije.2017.5101.

[5] E. F. Zeer and A. V. Streltsov, "Technological platform for realization of students' individual educational trajectories in a vocational school," Math. Educ., vol. 11, no. 7, 2016.

[6] Z. H. U. Aiqun, "An IT capability approach to informatization construction of higer 
education institutions," in Procedia Computer Science, 2018, vol. 131, doi: 10.1016/j.procs.2018.04.312.

[7] S. Sharov, O. Filatova, and T. Sharova, "The development of an online platform for studying Ukrainian literature," TEM J., vol. 9, no. 3, 2020, doi: 10.18421/TEM93-43.

[8] M. L. Cacheiro-Gonzalez, A. Medina-Rivilla, M. C. Dominguez-Garrido, and M. Medina-Dominguez, "The learning platform in distance higher education: Student's perceptions," Turkish Online J. Distance Educ., vol. 20, no. 1, 2019, doi: 10.17718/tojde.522387.

[9] S. Sharov, A. Pavlenko, T. Sharova, and O. Chorna, "Analysis of Developers of Online Courses on Ukrainian Platforms of MOOC," Int. J. Emerg. Technol. Learn., vol. 16, no. 05, p. 201, Mar. 2021, doi: 10.3991/ijet.v16i05.18581.

[10] V. V. Zaporozhko, D. I. Parfenov, M. Lapina, and D. Sora, "Development and research of algorithms for the formation the individual educational trajectories of students in the digital educational platform," in CEUR Workshop Proceedings, 2019, vol. 2494.

[11] S. Pivneva, D. Denisova, N. Vitkovskaya, R. Zakieva, E. Muraya, and G. Ushakova, "Advanced information technology: Automated and individual learning systems," Int. J. Adv. Trends Comput. Sci. Eng., vol. 8, no. 6, pp. 3481-3487, Nov. 2019, doi: 10.30534/ijatcse/2019/125862019.

[12] A. V Morozov and T. A. Vakaliuk, "An electronic environment of higher education institution (on the example of Zhytomyr Polytechnic State University)," J. Phys. Conf. Ser., vol. 1840, no. 1, p. 012061, Mar. 2021, doi: 10.1088/1742-6596/1840/1/012061.

[13] U. Khamdamov, A. Abdullayev, J. Elov, and D. Sultanov, "Conceptual model of the education management information system for higher education institutions," Int. J. Adv. Trends Comput. Sci. Eng., vol. 9, no. 5, pp. 7295-7300, Sep. 2020, doi: 10.30534/ijatcse/2020/59952020.

[14] H. Baharun, "Management information systems in education : the significance of epublic relation for enhancing competitiveness of higher education," in Journal of Physics: Conference Series, 2019, vol. 1175, no. 1, doi: 10.1088/17426596/1175/1/012151.

[15] A. Nguyen, T. Tuunanen, L. Gardner, and D. Sheridan, "Design principles for learning analytics information systems in higher education," Eur. J. Inf. Syst., 2020, doi: 10.1080/0960085X.2020.1816144.

[16] M. Vinnyk, M. Poltorackiy, Y. Spivakovska, T. Vinnyk, L. Bondarenko, and Y. Revenko, "Measuring the effectiveness of the implementation of individual educational trajectories by university students," in CEUR Workshop Proceedings, 2020, vol. 2732, pp. 1286-1297. 